\title{
Lipids, lysosomes and mitochondria: insights into Lewy body formation from rare monogenic disorders
}

\author{
Daniel Erskine ${ }^{1,2}$ (1) $\cdot$ David Koss $^{1} \cdot$ Viktor I. Korolchuk $^{3} \cdot$ Tiago F. Outeiro $^{1,4,5,6} \cdot$ Johannes Attems $^{1} \cdot$ lan McKeith $^{1}$
}

Received: 22 December 2020 / Revised: 13 January 2021 / Accepted: 15 January 2021 / Published online: 30 January 2021

(c) The Author(s) 2021

\begin{abstract}
Accumulation of the protein $\alpha$-synuclein into insoluble intracellular deposits termed Lewy bodies (LBs) is the characteristic neuropathological feature of LB diseases, such as Parkinson's disease (PD), Parkinson's disease dementia (PDD) and dementia with LB (DLB). $\alpha$-Synuclein aggregation is thought to be a critical pathogenic event in the aetiology of LB disease, based on genetic analyses, fundamental studies using model systems, and the observation of LB pathology in post-mortem tissue. However, some monogenic disorders not traditionally characterised as synucleinopathies, such as lysosomal storage disorders, iron storage disorders and mitochondrial diseases, appear disproportionately vulnerable to the deposition of LBs, perhaps suggesting the process of LB formation may be a result of processes perturbed as a result of these conditions. The present review discusses biological pathways common to monogenic disorders associated with LB formation, identifying catabolic processes, particularly related to lipid homeostasis, autophagy and mitochondrial function, as processes that could contribute to LB formation. These findings are discussed in the context of known mediators of $\alpha$-synuclein aggregation, highlighting the potential influence of impairments to these processes in the aetiology of LB formation.
\end{abstract}

Keywords Lewy body $\cdot$ Alpha-synuclein $\cdot$ Lipid metabolism $\cdot$ Autophagy $\cdot$ Catabolism $\cdot$ Mitochondria

\section{Introduction}

The Lewy body (LB) diseases, including Parkinson's disease (PD), Parkinson's disease dementia (PDD) and dementia with LBs (DLB), are thought to lie on a clinical and pathological continuum of motor and cognitive symptoms [60].

Daniel Erskine

daniel.erskine@ncl.ac.uk

1 Newcastle University Translational and Clinical Research Institute, Newcastle University, Newcastle upon Tyne, UK

2 Wellcome Centre for Mitochondrial Research, Newcastle upon Tyne, UK

3 Newcastle University Biosciences Institute, Newcastle University, Newcastle upon Tyne, UK

4 Department of Experimental Neurodegeneration, Center for Biostructural Imaging of Neurodegeneration, University Medical Center Goettingen, Goettingen, Germany

5 Max Planck Institute for Experimental Medicine, Goettingen, Germany

6 Scientific Employee With an Honorary Contract at Deutsches Zentrum Für Neurodegenerative Erkrankungen (DZNE), Göttingen, Germany
PD presents with a rest tremor, bradykinesia and an unsteady gait, that can develop into dementia termed PDD, whilst DLB presents with cognitive impairment that can later develop into motor symptoms similar to PD [75]. All LB diseases are characterised by the accumulation of the protein $\alpha$-synuclein into spherical intracellular deposits termed LBs $[75,115]$. The central role of $\alpha$-synuclein in LB diseases originated from the finding of mutations in the $\alpha$-synuclein gene SNCA causing familial PD [94], and the presence of $\alpha$-synuclein in LB pathology [115]. Although there is continued controversy surrounding the direct relevance of LBs to the clinical features of LB diseases (LBDs), the aggregation of $\alpha$-synuclein is thought to be a critical event in the development of LBDs [88].

The native structure of $\alpha$-synuclein is thought to dynamically shift between an unstructured monomer and a helically folded tetramer, with disassembly of tetramers into aggregation-prone monomers thought to be crucial for the aggregation propensity of $\alpha$-synuclein [9, 25, 85]. The aggregation of $\alpha$-synuclein is thought to occur in two stages, characterised initially by a nucleation phase where soluble monomers form into transient oligomers, prior to being built upon during an exponential elongation phase that produces filaments 
that are incorporated into fibrillary structures, such as LBs [82]. The application of exogenous fibrils to cells in culture induces the misfolding of monomeric $\alpha$-synuclein, leading to accumulation of loosely organised filaments, prior to reorganisation of fibrils into spherical LB-like lesions over time [72]. However, the direct functional consequences of LB formation on cell viability remains elusive, with some studies highlighting the potential importance of an ill-defined pool of pre-fibrillar oligomers as the primary causative agents of neurodegeneration in LB disease [2], recent studies have suggested LB-like aggregates to be the primary drivers of neurodegeneration $[72,101]$. Despite controversies surrounding the role of LBs in neurodegeneration in LB disease, the central role ascribed to $\alpha$-synuclein aggregation in LB diseases means that understanding the genesis of $\alpha$-synuclein aggregation is a pressing issue.

Although LBs are typically thought to be the hallmark pathological lesion associated with LB diseases, they are also observed in cases of several rare genetic disorders, including some forms of familial PD [8], neurodegeneration with brain iron accumulation (NBIA) [104], lysosomal storage disorders [108] and mitochondrial diseases [28]. In these conditions, the proportion of cases that manifest LBs is higher than would be expected in a comparable control population, implying a relationship between the genetic defect giving rise to the disease and LB formation. Furthermore, as LB disease and asymptomatic incidental LBs are typically only observed in elderly individuals, the young age at which LBs have been reported in some disorders implies that these are not simply incidental occurrences.

If LBs are a consequence of perturbed functioning of particular cellular pathways, then understanding the underlying cause of rare genetic disorders characterised by LBs could provide insights into LB formation. The present review will summarise the range of disorders in which LBs have been reported, and discuss how a holistic view of this disparate range of diseases may generate insights into LB formation in idiopathic LB disease. The review is not intended to be a comprehensive summary of disorders with a parkinsonian phenotype, and is focused instead on attempting to understand why LBs may form in idiopathic LBD by examining monogenic disorders with evidence of LB pathology on neuropathological examination.

\section{Monogenic diseases associated with a-synuclein pathology}

\section{Familial PD}

Whilst the majority of PD cases are idiopathic, a significant minority result from genetic mutations with varying patterns of clinical features and neuropathological lesion formation. An increasing number of genes have been associated with familial PD, with varying similarity to idiopathic PD, and these have been reviewed elsewhere [8]. Familial PD syndromes are highly clinically heterogenous in terms of age of onset and clinical presentation, though all typically include parkinsonian motor features, but can vary from that observed in idiopathic LBD. However, the present review will only discuss those forms of familial PD that have documented evidence of LB pathology, or a higher rate of LB pathology than would be expected in a comparable control population, and includes mutations in SNCA [64, 73, 92, 106, 137], LRRK2 [98], DNAJC13 [131], PRKN [103], PINK1 [100, 116, 127], DJ-1/PARK7 [126], TMEM230 [24] and LRP10 [95, 129], as described in Table 1. While some, such as $P R K N$, may seem controversial as only approximately $33 \%$ of cases manifest LBs, leading to its characterisation as a primary nigropathy [27], as incidental LBs occur in only $10 \%$ of the normal elderly population [28] one could suggest $P R K N$ mutations are associated with increased risk of LB pathology. Rodent models of SNCA [30], LRRK2 [10], DNAJC13 [135], PRKN [70], and PINK1 [19] are associated with $\alpha$-synuclein aggregation. In contrast, there have been no studies investigating $\alpha$-synuclein in rodent models of PARK7, TMEM230, or LRP10.

\section{NBIA}

Iron is present throughout the brain, where it is involved in several important functions including energy production, DNA repair, phospholipid metabolism and myelination [20, 33]. NBIA are a range of disorders characterised by cerebral iron accumulation, giving rise to a range of neurodegenerative diseases that are distinguished into sub-types on the basis of the gene that causes them. Irrespective of underlying genetic cause, spasticity and dystonia are typical presenting features, and onset is often in early life, including infancy $[7,104]$. A comprehensive review of the genetics, pathophysiology and neuropathology of NBIA has already been conducted [104]; therefore, the present discussion will focus only on NBIA disorders in which LBs have been reported: PLKA2G6-associated neurodegeneration (PLAN) [90] and mitochondrial membrane protein associated neurodegeneration (MPAN) $[44,49,54]$ as described in Table 1. LBs are an invariant finding in every neuropathological case reported in the literature, including in a PLAN case aged 8 and an MPAN case aged 23, much younger than the earliest age at which incidental LBs have been reported in control populations, which is typically approximately 60 years old [34, 88]. A rodent model of PLA2G6 knockout demonstrated widespread $\alpha$-synuclein aggregation, particularly on mitochondrial membranes [122], though there are no studies of 


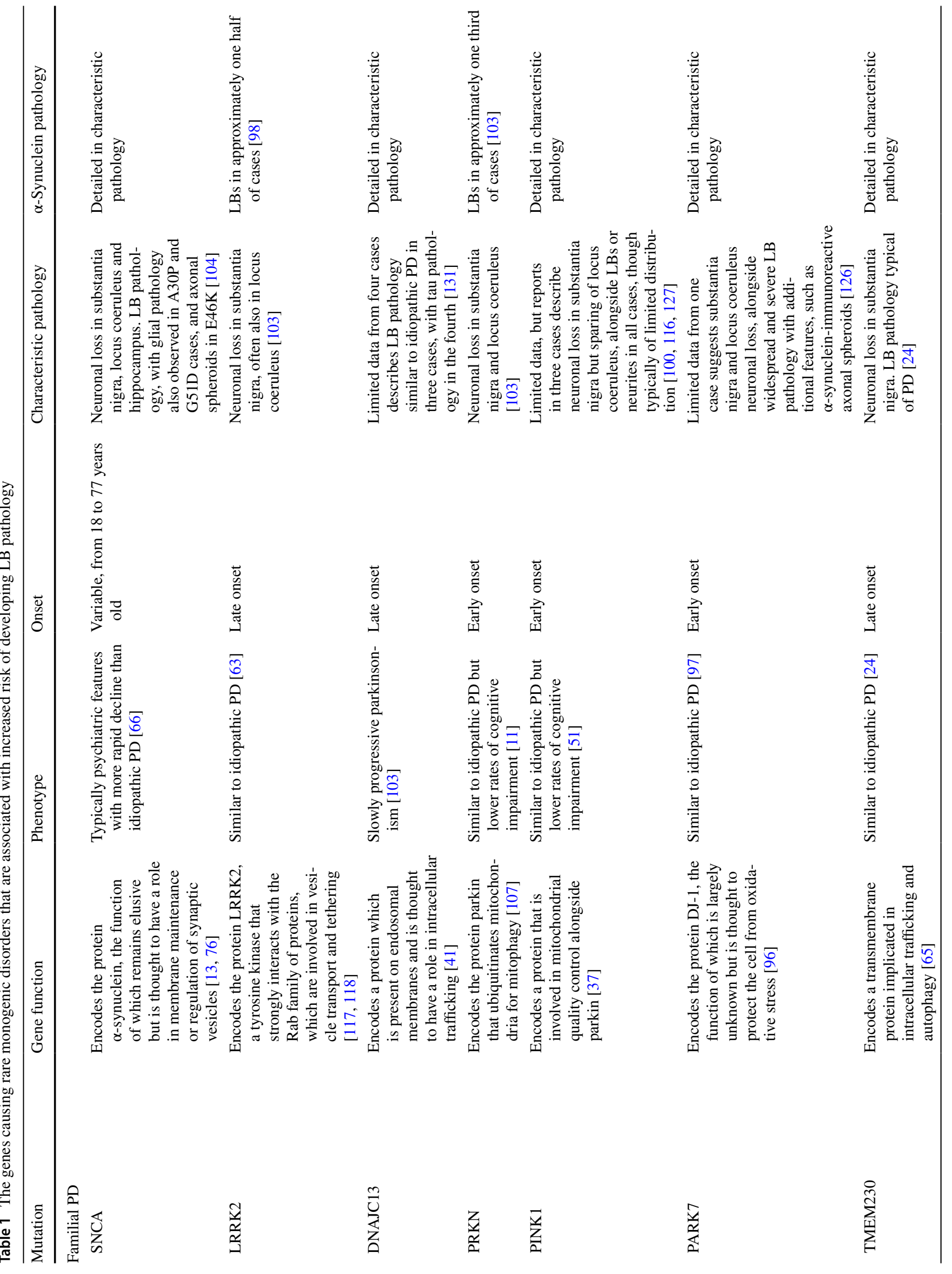




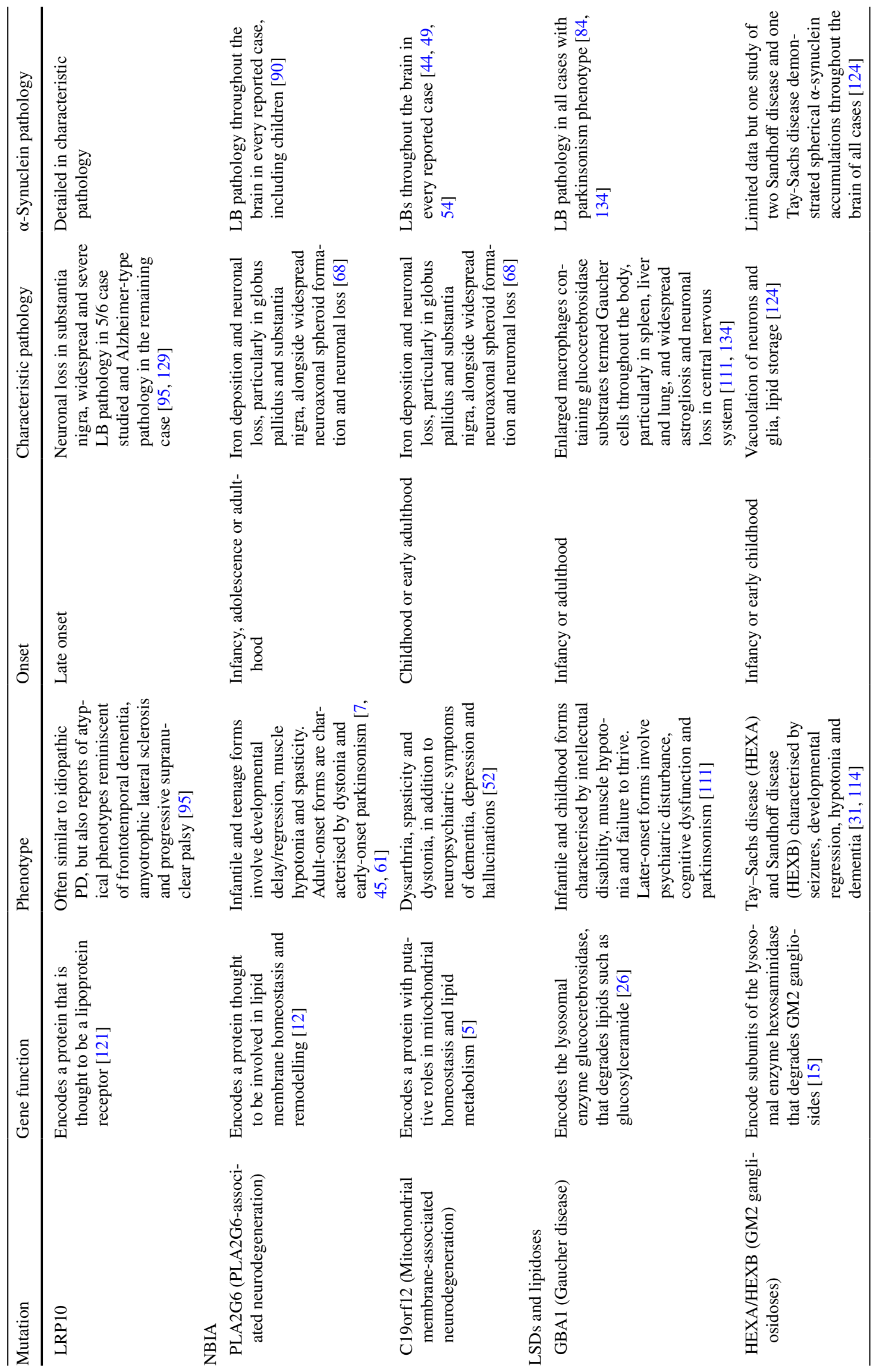




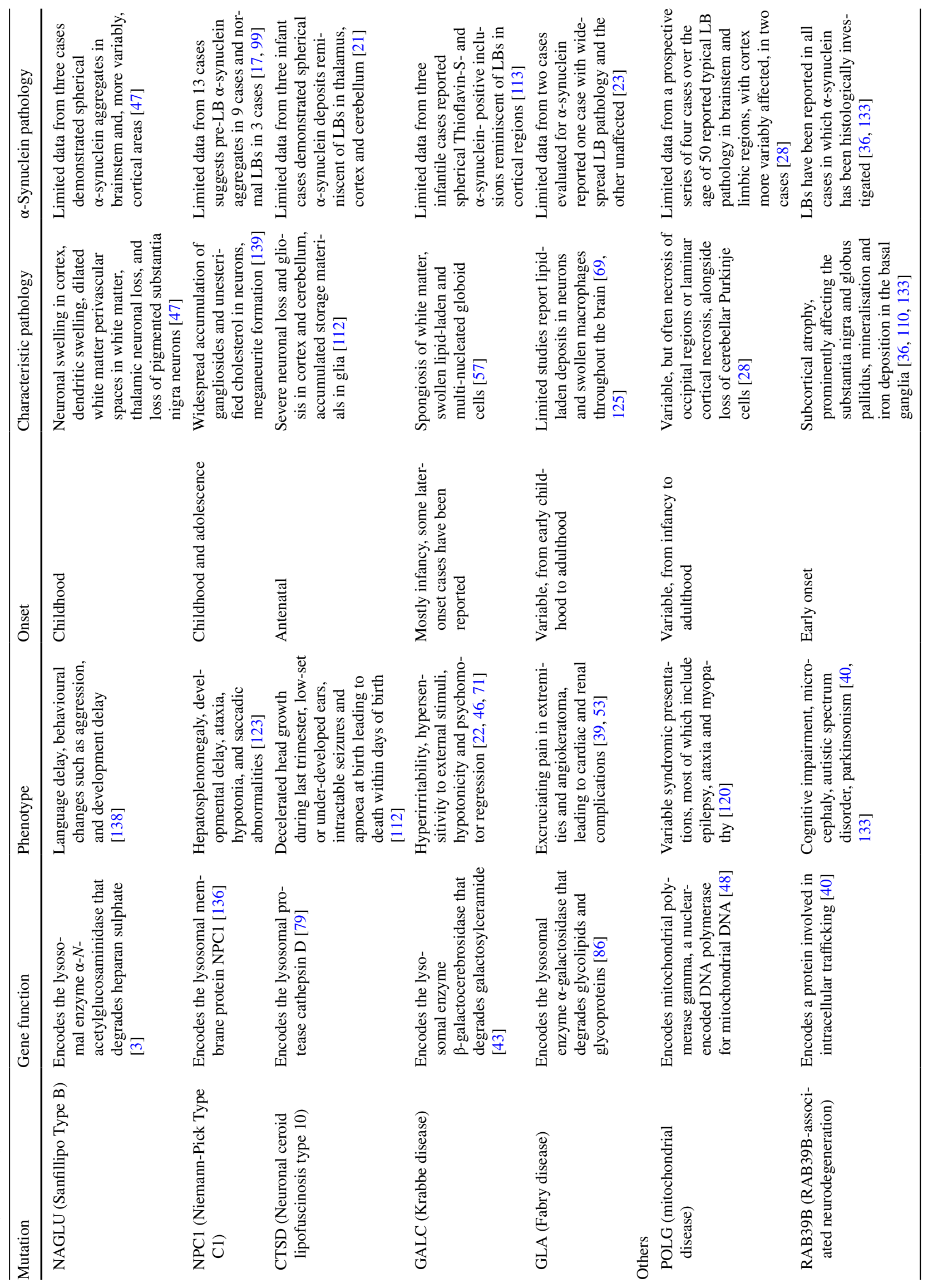


$\alpha$-synuclein aggregation in rodents with C19orf12 mutation or deletion to our knowledge.

\section{Lysosomal storage disorders and lipidoses}

Lysosomal storage disorders (LSD) are caused by mutations in the genes that encode either lysosomal enzymes or membranes, resulting in impaired lysosomal breakdown of cellular components and accumulation of waste products within cells, particularly those within the central nervous system [108]. Lipidoses are disorders characterised by altered lipid metabolism, often by mutations in lysosomal enzymes, resulting in accumulated lipids in vulnerable cells [124]. LSD and lipidoses typically present in infancy or early childhood, though some cases can occur up to adulthood, and whilst clinically heterogeneous are usually characterised by developmental delay or regression, and hypotonia [31]. Detailed neuropathological reports from many of the rare mutations causing LSD and lipidoses are lacking, so the present discussion will focus on those with reported $\alpha$-synuclein pathology: Gaucher disease [84], GM2 gangliosidosis [124], Sanfilippo syndrome [47], Niemann-Pick disease Type CI [99], neuronal ceroid lipofuscinosis type 10 [21], Fabry disease [23] and Krabbe disease [113], as described in Table 1.

Many lipidoses are plausibly linked to the aggregation of $\alpha$-synuclein as they result from loss of function of lipiddegrading enzymes, the substrates of which have been demonstrated to induce the aggregation of $\alpha$-synuclein in vitro. For example, Krabbe disease results from mutations in $G A L C$ encoding the enzyme galactosylceramidase, resulting in the accumulation of the cytotoxic lipid psychosine which has been demonstrated to induce to fibrillization of $\alpha$-synuclein in vitro [113] through direct interactions with its $\mathrm{C}$-terminal region that expose the central amyloidogenic region [1]. Sanfillipo Type B results from loss-of-function mutations in the lysosomal enzyme $\alpha-N$ acetylglucosaminidase, leading to accumulation of its substrate heparan sulphate [3], which increases the rate of $\alpha$-synuclein fibrillization in a dose-dependent manner in vitro, possibly by binding the $\mathrm{N}$-terminus and inducing conformational changes permissive to fibrillation [18]. The influence of lipidosis-causing genetic mutations may be two-fold, with both reduced clearance of $\alpha$-synuclein due to autophagic impairments leading to a state of increased abundance of $\alpha$-synuclein within cells, combined with the accumulation of lipids known to promote $\alpha$-synuclein aggregation, as has been demonstrated for GBA1 [119].

It is notable that most cases in the literature have reported $\alpha$-synuclein pathology in cases deceased in infancy or childhood, much earlier than incidental LBs typically develop. However, it is not clear to what extent $\alpha$-synuclein pathology in LSDs and lipidoses is similar to that observed in idiopathic LBD in terms of its capacity to induce native $\alpha$-synuclein to misfold, underlying the need for further studies on the ultrastructure and seed-competency of LB pathology in rare LSDs and lipidoses. Representative images of $\alpha$-synuclein immunoreactivity in an infantile Krabbe disease case obtained prospectively can be found in Fig. 1 (A-B.i.). Rodent models of Gaucher disease (GBAl) [56], Sandhoff disease (HEXA) [62], Tay-Sachs disease (HEXB) [14],
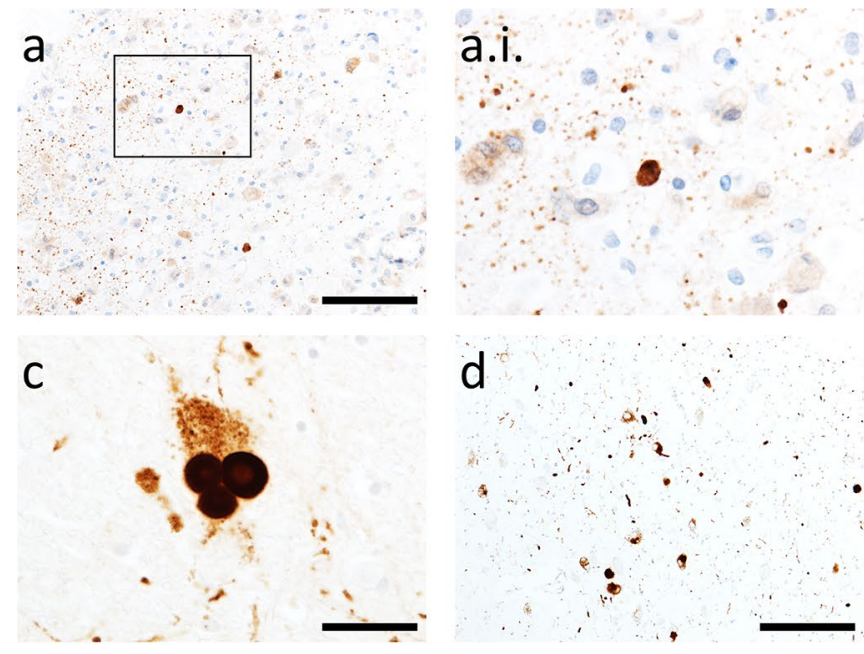

Fig. $1 \alpha$-Synuclein immunoreactivity in rare monogenic disorders in comparison to idiopathic LB diseases. $\alpha$-Synuclein-positive punctae and small, LB-like structures, in temporal cortex grey-white matter junction in a 10 month old boy with Krabbe disease (a and a.i.) in comparison to superficial pyramidal layer of temporal cortex in a 91-year-old female with dementia with LBs (b-b.i.). LBs in substantia nigra (c) and nucleus basalis of Meynert (d) of a 87-year-

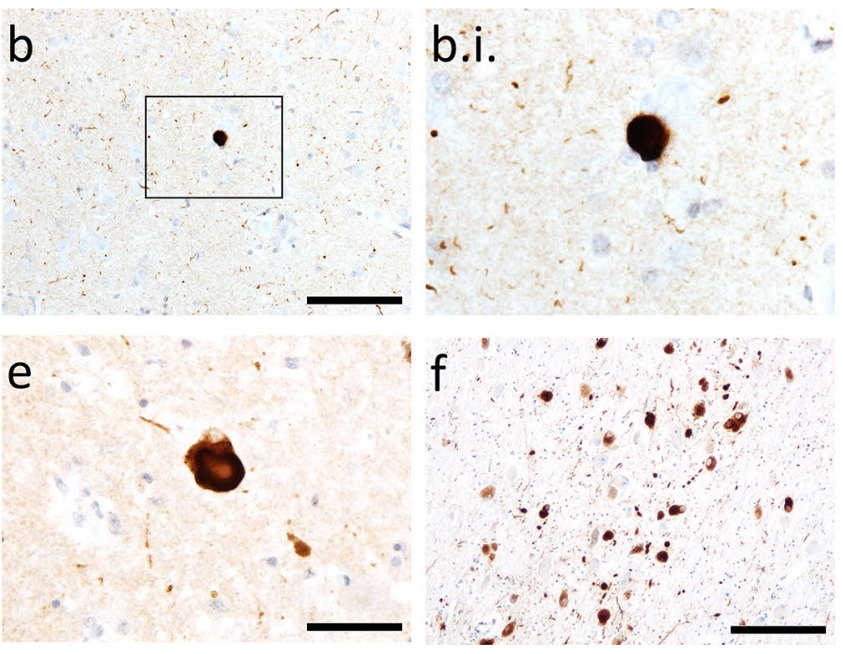

old female with dementia with LBs in comparison to the substantia nigra (e) and nucleus basalis of Meynert (f) of a 79-year-old male with a $P O L G$ mutation and longstanding progressive external opthalmoplegia taken from our previous report of LB pathology in mitochondrial disease [28]. Antibodies used were BD Transductions Clone $42(1: 1,000 ; \mathbf{a}-\mathbf{b . i}$.$) and Novocastra KM51 (1:250; c-f). Scale$ bars $=100 \mu \mathrm{m}(\mathbf{a}$ and $\mathbf{b}), 50 \mu \mathrm{m}(\mathbf{c}$ and $\mathbf{e})$ and $200 \mu \mathrm{m}(\mathbf{d}$ and $\mathbf{f})$ 
neuronal ceroid lipofuscinosis type 10 (CATD) [21], Krabbe disease $(G A L C)$ [113], and Fabry disease (GLA) [83] manifest accumulated insoluble $\alpha$-synuclein. In contrast, no study has yet investigated whether $\alpha$-synuclein is accumulated in Sanfillipo syndrome $(N A G L U)$ or Niemann-Pick Type C1 $(N P C 1)$ rodent models.

\section{Mitochondrial diseases}

Mitochondrial diseases result from mutations in either nuclear or mitochondrial DNA, inducing perturbed cellular respiration and degeneration of cellular populations with the highest energy requirement [42]. Mitochondrial diseases are heterogeneous entities, even across cases with the same mutation, and age of onset, clinical presentation and neuropathological features can vary [42]. POLG encodes polymerase gamma, a nuclear-encoded DNA polymerase for mitochondrial DNA, mutations in which give rise to several clinical syndromes, including: Alpers-Huttenlocher syndrome (AHS), myocerebrohepatopathy spectrum (MCHS), myoclonic epilepsy myopathy sensory ataxia (MEMSA), ataxia neuropathy spectrum (ANS) and progressive external ophthalmoplegia (PEO) [120]. We have reported a higher prevalence of LB pathology in a prospective series of older mitochondrial disease cases, particularly those with POLG mutations, compared to a control population [28], as described in Table 1. Representative images of cortical and midbrain LBs in a 79-year-old individual with a $P O L G$ mutation, in comparison to an individual with dementia with LBs, can be found in Fig. 1c-f. To the best of our knowledge, no study has yet evaluated $\alpha$-synuclein aggregation in $P O L G$ mice.

\section{RAB39B-associated neurodegeneration}

A number of RAB39B mutations resulting in the loss of expression/function of the protein are associated with $\mathrm{X}$-linked mental retardation, autistic spectrum disorder and early onset PD, as described in Table $1[40,133]$. Although somewhat heterogeneous in terms of symptom presentation, lifelong non-progressive cognitive impairment with underlying macrocephaly is common, as is early onset PD, occurring between 10 and 50 years of age [40, 133]. In those limited cases where $\alpha$-synuclein immunoreactivity has been investigated, both subcortical and cortical LBs were reported [36, 133]. Furthermore, we have recently reported RAB39B as reduced in post-mortem LBD brain tissue and sequestered into some LBs, potentially indicating a role for RAB39B in idiopathic LBD [67]. To the best of our knowledge, $\alpha$-synuclein aggregation has not yet been investigated in $R A B 39 B$ rodent models.

\section{Gene ontology analysis of risk genes for LB pathology}

To better understand commonalities across the range of genetic disorders in which LBs are observed, we used both the Gene Ontology Resource $[6,128]$ with PANTHER gene enrichment software [77], and ShinyGO [38], to identify common biological processes enriched in these genes associated with LB pathology.

Analysis using PANTHER demonstrated enrichment of biological processes related to mitochondrial function (negative regulation of hydrogen peroxide-induced neuron intrinsic apoptotic signalling pathway, regulation of peroxidase activity, mitochondrion to lysosome transport, positive regulation of mitochondrial electron transport, positive regulation of mitophagy in response to mitochondrial

Table 2 Analysis with PANTHER [77] demonstrated enrichment for genes implicated in mitochondrial function

\begin{tabular}{lcc}
\hline GO biological process & Fold enrichment & $P$ value \\
\hline $\begin{array}{l}\text { Negative regulation of hydrogen peroxide-induced neuron intrinsic apoptotic signal- } \\
\text { ling pathway }\end{array}$ & $>100$ & $5.23 \mathrm{E}-06$ \\
Regulation of peroxidase activity & $>100$ & $1.11 \mathrm{E}-03$ \\
Mitochondrion to lysosome transport & $>100$ & $8.71 \mathrm{E}-06$ \\
Positive regulation of mitochondrial electron transport, NADH to ubiquinone & $>100$ & $8.71 \mathrm{E}-06$ \\
Regulation of synaptic vesicle transport & $>100$ & $8.71 \mathrm{E}-06$ \\
Regulation of retrograde transport, endosome to Golgi & $>100$ & $8.99 \mathrm{E}-08$ \\
Positive regulation of histone deacetylase activity & $>100$ & $1.61 \mathrm{E}-03$ \\
Ganglioside catabolic process & $>100$ & $7.56 \mathrm{E}-03$ \\
Glycosylceramide catabolic process & $>100$ & $2.43 \mathrm{E}-05$ \\
Positive regulation of mitophagy in response to mitochondrial depolarization & $>100$ & $3.13 \mathrm{E}-05$ \\
\hline
\end{tabular}

Top ten enriched processes when ranked based on FDR are shown 
depolarization), lysosomal degradation (regulation of peroxidase activity, mitochondrion to lysosome transport, regulation of retrograde transport endosome to Golgi, positive regulation of mitophagy in response to mitochondrial depolarization) and lipid catabolism (ganglioside catabolic process, glycosylceramide catabolic process; Table 2).

Evaluation of the genes associated with LB pathology using ShinyGo largely confirmed the findings from PANTHER, with enriched biological processes functionally clustered around two sub-groups of mitochondrial function/autophagy, and lipid metabolism, linked by catabolism (Fig. 2).

\section{Lipids, lysosomes, mitochondria and LB pathology}

One of the primary reasons for the ascendency of $\alpha$-synuclein in LB disease is that it is responsible for mutations causing the first identified form of familial PD and is a component of LBs [88]; however, a recent study has reported that the core of LBs may be composed of lipids and surrounded by dystrophic mitochondria [109]. The novel report of LBs as having a lipid core has led to considerable debate in the field as to whether LBDs are indeed proteopathies or whether they should be considered a lipidopathy [29]. By evaluating the spectrum of monogenic disorders in which LBs are frequently observed we have continued this debate by identifying that alterations to lipid metabolism,

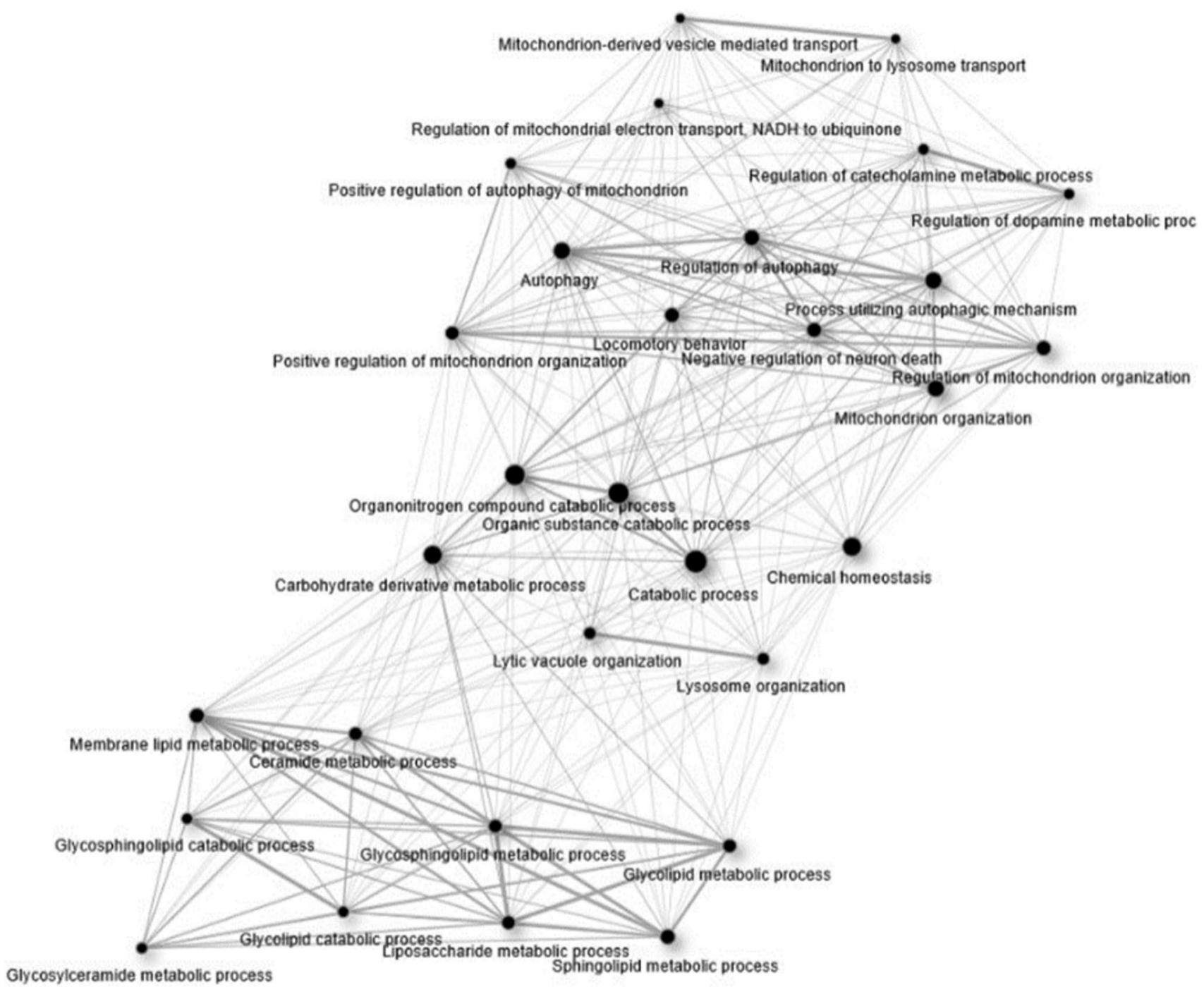

Fig. 2 ShinyGO [38] analysis demonstrated three broad clusters into which enriched biological processes clustered: lipid metabolism, catabolic processes, and mitochondrial homeostasis and autophagy 
Fig. 3 LB dementia is associated with changes to the mitochondrial respiratory chain. Representative images from our previous study in the nucleus basalis of Meynert [50] demonstrating respiratory chain subunit expression in control (A.i.-A.iv.), incidental LB disease (iLBD) (B.i.-B. iv.) and LB dementia (LBD) (C.i.-C.iv.) cases, highlighting reductions in Complex I in LBD compared to iLBD and control. As detailed in [50], sections were stained with ChAT (Sigma HPA048547, 1:100), NDUFB8 (Abcam ab110242, 1:100), COX4 (Abcam ab110261, $1: 100)$ and VDAC1/porin (Abcam ab14734, 1:200). Scale bars $=10 \mu \mathrm{m}$. Dot plots show group level z scores of Complex I NDUFB8 and IV/COXIV integrated densities normalised to porin integrated density, as explained in detail in [50], from approximately 50 neurons per case (control $N=8$, LBD $N=8$, iLBD $N=2$ ). Bars are means and standard deviation. $* p<0.05$. Originally published in [50] by BioMed Central and provided here under a Creative Commons Attribution Licence 4.0
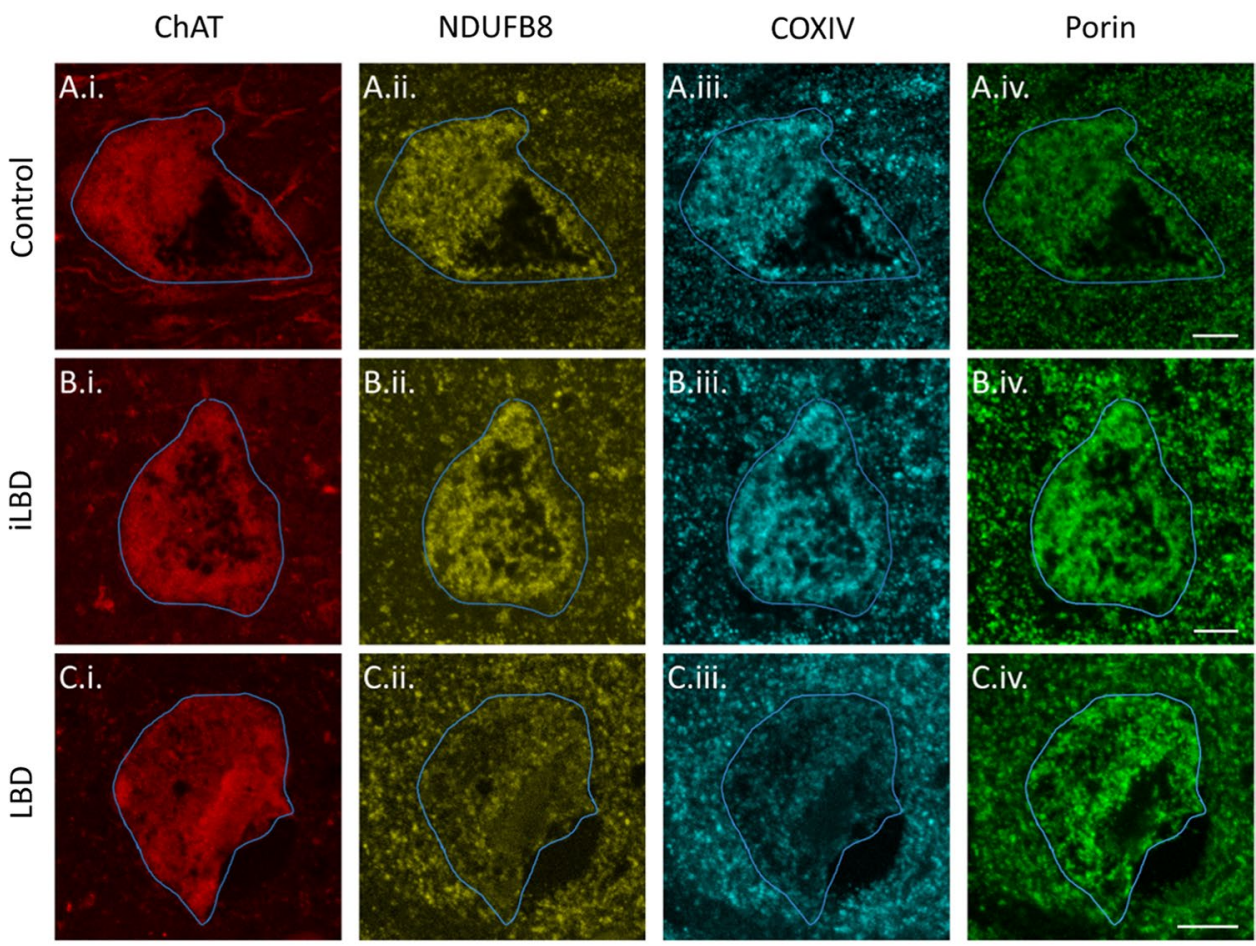

Complex I/porin

Complex IV/porin
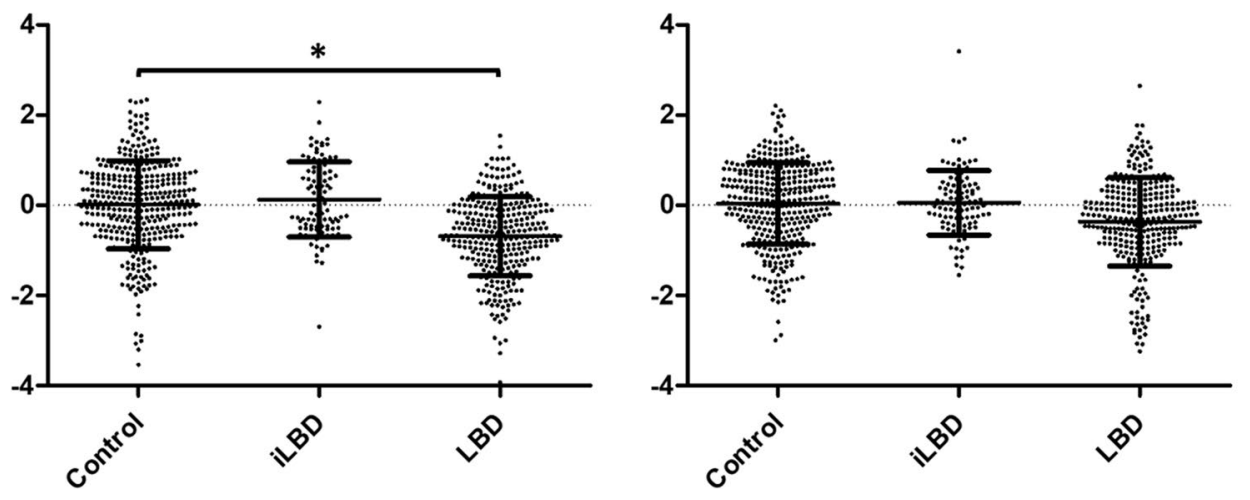

autophagy and mitochondrial function are common pathways affected in the genetic mutations associated with LB pathology. Thus, a key question is how alterations to these distinct processes contribute to $\alpha$-synuclein aggregation and the formation of LBs.

Deficits in mitochondrial energy production have long been implicated in LB diseases, from the early identification of complex I inhibitors causing parkinsonism and $\alpha$-synuclein aggregation, to the identification of mutations in mitochondrial proteins causing familial PD [16]. Alterations to the mitochondrial respiratory chain are a consistent finding in LB diseases, and we have previously reported reductions in Complex I of the mitochondrial respiratory chain in cholinergic nucleus basalis of Meynert neurons in LB dementia (Fig. 3) [50]. Energy production is an attractive hypothesis to explain the potential contribution of lipid metabolism, autophagy and mitochondrial function to LB formation, as catabolic processes were implicated in the GO analysis. Cellular energy in the form of adenosine triphosphate (ATP) is primarily produced in mitochondria, where glucose is broken down by glycolysis to form pyruvate, which is then converted to the metabolic intermediate acetylCoenzyme A (acetyl-CoA) to enter the citric acid cycle and mitochondrial respiratory chain to generate ATP [87]. Deficient energy production may contribute to $\alpha$-synuclein aggregation through excessive production of reactive oxygen species (ROS), leading to the accumulation of oxidised $\alpha$-synuclein that is more resistant to degradation [74]. It has also been suggested that increasingly oxidised intracellular environments may lead to reductions in binding partners of $\alpha$-synuclein, increasing levels of unbound $\alpha$-synuclein, culminating in its aggregation [102]. 
Autophagy is a critical process that degrades mitochondria, lipids, and many other organelles or macromolecules, the accumulation of which can significantly impair cellular functioning, and there are multiple lines of evidence from model systems and post-mortem tissue indicating it is deficient in LB disease [55]. Whilst autophagic deficits have intuitive appeal for promoting $\alpha$-synuclein aggregation by impeding its degradation, it is not clear how deficits in a relatively non-specific process like autophagy would selectively induce $\alpha$-synuclein accumulation and not that of other aggregation-prone proteins. A recent study reported that LBs contain numerous lipids, dystrophic mitochondria and other organelles, and thus one could speculate they are accumulating and compartmentalising damaged organelles and macromolecules as a protective mechanism in the context of deficient autophagic processes [109]. In this context, $\alpha$-synuclein aggregation could be a stereotyped response to autophagy failure with the aim of protecting the cell from the deleterious effects of accumulated macromolecules and organelles such as mitochondria. Consistent with a putative protective role for LBs, we have previously reported that neurons of the nucleus basalis of Meynert harbour mitochondrial respiratory chain deficits and increased levels of mitochondria in LB dementia, but that neurons with LBs have fewer deficits [50]. However, autophagic processes play a critical role in mitochondrial quality control through selective mitochondrial degradation termed mitophagy, and there is evidence to suggest this is impaired in LB diseases, thus suggesting autophagic deficits could induce accumulation of dysfunctional mitochondria [32, 91]. Furthermore, our recent work indicates $\mathrm{NAD}(\mathrm{H})$, an essential cofactor for mitochondrial metabolism, is depleted by selective inhibition of autophagy, demonstrating that deficient autophagy induces mitochondrial dysfunction [105]. In summary, whilst autophagy may relate to $\alpha$-synuclein aggregation by impeding its degradation, this seems a sub-optimal explanation given the likely impact this would have on aggregation-prone proteins beyond $\alpha$-synuclein. Therefore, it seems more likely that the impact of autophagy impairments on $\alpha$-synuclein aggregation may implicate other cellular processes, such as a hypothesised protective role or an impact upon mitochondrial function or quality control, and that this underlies the apparent selective accumulation of $\alpha$-synuclein in the context of autophagic deficits.

Lipid homeostasis is vital for cellular health as the accumulation of lipids within cells induces the cellular stress response and lysosomes play a key role in preventing lipid accumulation by degrading lipids in a selective autophagic process termed lipophagy, and also by acting as a nutrient sensor to regulate lipophagy [58]. Thus, autophagy is critical for the maintenance of lipid homeostasis. However, mitochondria are also a major site of intracellular lipid degradation as they are the site of fatty acid $\beta$-oxidation, the catabolic process that breaks down fatty acids to generate acetyl-CoA [80]. Intracellular accumulation of lipids leads to excessive production of ROS and decreased mitochondrial biogenesis, inducing a state of decreased mitochondrial respiratory function and diminished ATP production, in turn leading to decreased mitochondrial degradation of lipids and further lipid accumulation [59]. Accumulation of lipids, or at least dyshomeostasis amongst lipid species in the brain, may have a direct influence on $\alpha$-synuclein aggregation as lipid membrane surfaces have been proposed as a potential site of $\alpha$-synuclein aggregation, with the degree of membrane binding inversely proportional to the propensity of $\alpha$-synuclein to polymerise [130]. Furthermore, exposure of $\alpha$-synuclein to polyunsaturated fatty acids such as arachidonic acid and linoleic acid has been demonstrated to induce rapid aggregation of $\alpha$-synuclein [35, 93], and we have previously demonstrated that $\alpha$-synuclein aggregation also promotes accumulation of lipids [89], potentially creating a cycle of increasing lipid and $\alpha$-synuclein aggregation. Therefore, it is plausible to suggest that accumulations of particular lipids contribute to the aggregation of $\alpha$-synuclein, perhaps by inducing conformational changes that are permissive to aggregation [81]. It is notable that accumulation of lipids within cells could occur secondarily to diminished mitochondrial capacity to perform $\beta$-oxidation or impaired autophagic degradation of lipids.

Given the interrelated nature of lipid homeostasis, mitochondrial function and autophagy, it would be possible to make a case for any one of these three aspects underlying $\alpha$-synuclein aggregation in LBD, either directly or indirectly (Fig. 4). However, such reductionism overlooks the dynamic nature of cellular metabolism, and thus one could speculate that these impairments may act in concert to drive vulnerability to LB formation. Such a triad of impairments could potentially explain why cell death precedes LB formation in the substantia nigra [78], and neuronal loss occurs in regions without LB pathology in PD [4], as factors that govern cellular vulnerability to LB formation and cell death would likely differ between distinct neuronal sub-types. For example, if LB formation was driven by lipid dyshomeostasis, but cell death by mitochondrial dysfunction, then LBs would form first in neurons that normally have highest levels of the fatty acids permissive to $\alpha$-synuclein aggregation and cell death would occur first in neurons with the highest energy demands. It is plausible to suggest that the neuronal subclass with the highest energy demands may not be that with the highest levels of fatty acids permissive to $\alpha$-synuclein aggregation. Such a hypothesis does not preclude LBs being deleterious for cellular health, but rather would suggest they occur as a result of, and alongside, other changes that are likely to impact neuronal health. 


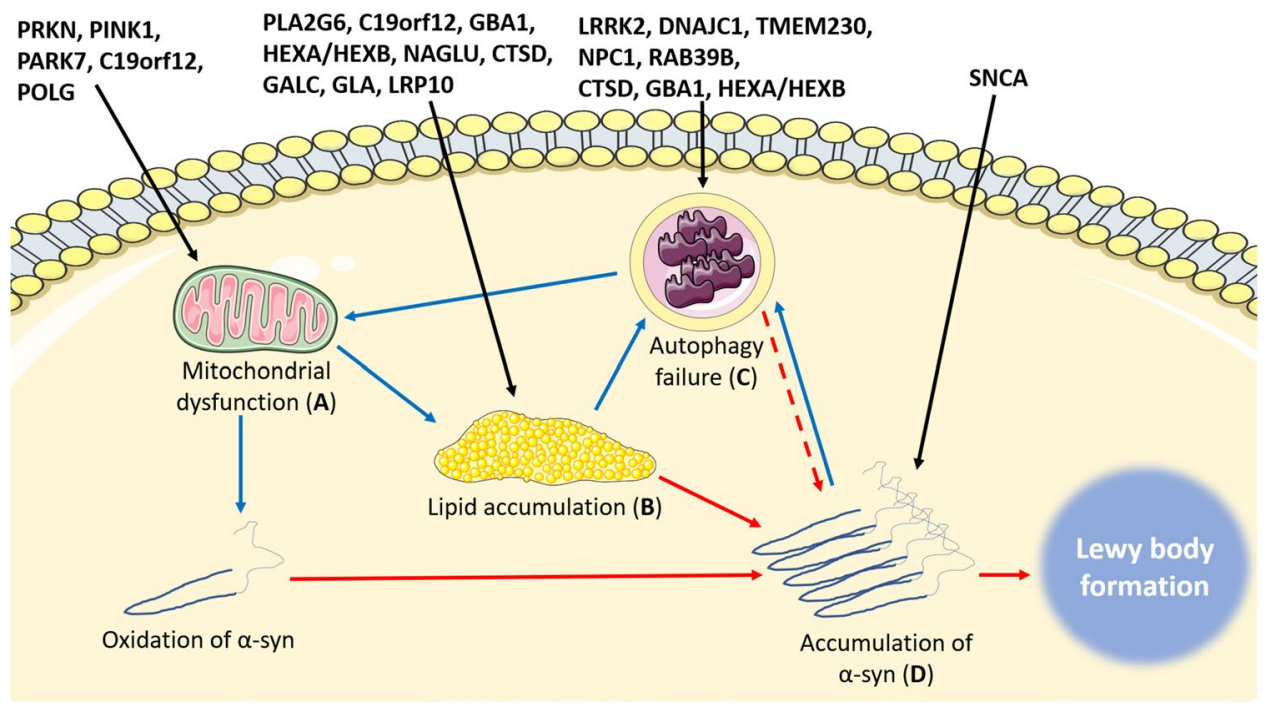

Fig. 4 Multiple pathways leading to Lewy body formation. a Mutations causing mitochondrial dysfunction may contribute to Lewy body formation by increasing oxidation of $\alpha$-synuclein, leading to aggregation and eventual formation of a Lewy body. b Mutations in genes encoding lipid-degrading enzymes such as GALC, GBA and CATD can directly lead to increased levels of lipid substrates known to be permissive to $\alpha$-synuclein aggregation, including psychosine, glucosylsphingosine and heparan sulphate, respectively. Alternatively, mitochondrial dysfunction (a) leads to increased abundance of lipid droplets known to facilitate $\alpha$-synuclein aggregation. Elevated levels of lipids are likely to overwhelm autophagic mechanisms within neurons, leading to autophagy failure after sustained elevations in

\section{Conclusion}

The present review has discussed a range of rare monogenic diseases that are disproportionately affected by LB pathology, on the basis that commonalities in biological pathways in which the protein products of the affected genes participate may provide insights into LB formation in idiopathic LB disease. In summarising the current published literature on $\alpha$-synuclein pathology in a diverse array of monogenic disorders, followed by GO analysis of the genes implicated in these disorders, autophagy, lipid metabolism and mitochondrial function emerge as common biological pathways. Impairments to these pathways could occur as a trio of impairments that underlie both the selective nature of LB formation in distinct neuronal populations and the selectivity of neurodegeneration in LB disease. It is important to note that there are many metabolic disorders, the majority of which do not seem to be vulnerable to LB formation, and thus it seems likely that there are specific pathways involved that are permissive to $\alpha$-synuclein aggregation, rather than general alterations to cellular metabolism.

Future studies are warranted to better characterise the structure of LBs, to further elucidate the lipid components within LBs and the lipid species that are most abundant. lipid species (c). c Autophagy failure induces mitochondrial dysfunction (a) by impeding mitochondrial quality control by reductions in mitophagy, and potentially also leads to $\alpha$-synuclein aggregation by reduced turnover (dashes). (d) Accumulation of $\alpha$-synuclein may occur directly due to disassembley of tetramers into aggregationprone monomers or increased abundance of $\alpha$-synuclein protein, or indirectly through (a), (b), or (c). Increased accumulation of $\alpha$-synuclein over time leads to assembly into Lewy bodies. Black lines indicate the mechanism directly affected by specific mutations, blue lines indicate indirect influences on $\alpha$-synuclein aggregation through interactions between mechanisms, and red lines indicate direct influences on $\alpha$-synuclein aggregation

Such studies may highlight aspects of lipid metabolic pathways that may be altered and give rise to LB pathology, directing future studies to explore mechanistic links between such dyshomeostasis and $\alpha$-synuclein aggregation. Furthermore, better characterisation of cellular metabolism, and how it is affected in LBD post-mortem brain tissue is also warranted, to better model how it may contribute to LB formation. For example, there is considerable evidence of mitochondrial respiratory chain dysfunction in LBD, but relatively little is known about peroxisomal function, despite their role in degrading very long chain fatty acids for mitochondrial $\beta$-oxidation and scavenging ROS placing them at a potentially pivotal juncture between lipid catabolism and mitochondrial energy production [132]. The role of processes other than $\alpha$-synuclein aggregation in LBDs is critically important for the field as considerable expense and effort is being expended targeting $\alpha$-synuclein aggregation as a potential disease-modifying therapy for LBD. However, if LB formation is itself a by-product of other altered cellular processes such as metabolic balance, then it would seem more likely to be effective to target amelioration of cellular metabolism than $\alpha$-synuclein aggregation.

A limitation of the present review is that some of the disorders covered are exceptionally rare, with neuropathological 
data limited to a small number of reports. Therefore, whilst the present review summarises the current state of knowledge on rare monogenic disorders disproportionately vulnerable to LBs, it is likely that there are further similar conditions vulnerable to LB pathology that have not been subject to detailed neuropathological evaluation of $\alpha$-synuclein. Furthermore, there may be a reporting bias in the prevalence of LBs in some conditions, as the presence of an ageassociated feature like LBs in young individuals may be more likely to be reported than more banal findings. It is also not clear whether $\alpha$-synuclein accumulations in many of the rare monogenic disorders has similar attributes to that observed in idiopathic LB disease, such as the propensity to seed aggregation of native $\alpha$-synuclein to spread in a 'prionlike' manner, or its contribution to clinical phenotype. The present review underlines the importance of further study of $\alpha$-synuclein aggregation in rare diseases to better understand the aetiology of LB formation in idiopathic LB disease and its biological relevance to the pathobiology of the rare diseases in which it is also observed.

Acknowledgements DE is funded by an Alzheimer's Research UK Fellowship (ARUK-RF2018C-005). DJK is funded by a research grant from The Lewy Bodies Society (LBS007). TFO is supported by the Deutsche Forschungsgemeinschaft (DFG, German Research Foundation) under Germany's Excellence Strategy-EXC 2067/1- 390729940, and by SFB1286 (Projects B6 and B8). Brain tissue provided for the images in this manuscript was provided by Newcastle Brain Tissue Resource, which is funded in part by a grant from the UK Medical Research Council (G0400074), by NIHR Newcastle Biomedical Research Centre awarded to the Newcastle upon Tyne NHS Foundation Trust and Newcastle University, and by a grant from the Alzheimer's Society and Alzheimer's Research UK as part of the Brains for Dementia Research Project. Figure 4 is adapted from images provided by Servier Medical Art by Servier and is provided under a Creative Commons Attribution 3.0 Unported License.

Open Access This article is licensed under a Creative Commons Attribution 4.0 International License, which permits use, sharing, adaptation, distribution and reproduction in any medium or format, as long as you give appropriate credit to the original author(s) and the source, provide a link to the Creative Commons licence, and indicate if changes were made. The images or other third party material in this article are included in the article's Creative Commons licence, unless indicated otherwise in a credit line to the material. If material is not included in the article's Creative Commons licence and your intended use is not permitted by statutory regulation or exceeds the permitted use, you will need to obtain permission directly from the copyright holder. To view a copy of this licence, visit http://creativecommons.org/licenses/by/4.0/.

\section{References}

1. Abdelkarim H, Marshall MS, Scesa G, Smith RA, Rue E, Marshall J et al (2018) alpha-Synuclein interacts directly but reversibly with psychosine: implications for alpha-synucleinopathies. Sci Rep 8:12462. https://doi.org/10.1038/s41598-018-30808-9

2. Alam P, Bousset L, Melki R, Otzen DE (2019) alpha-synuclein oligomers and fibrils: a spectrum of species, a spectrum of toxicities. J Neurochem 150:522-534. https://doi.org/10.1111/ jnc. 14808

3. Andrade F, Aldamiz-Echevarria L, Llarena M, Couce ML (2015) Sanfilippo syndrome: overall review. Pediatr Int 57:331-338. https://doi.org/10.1111/ped.12636

4. Ansorge O, Daniel SE, Pearce RK (1997) Neuronal loss and plasticity in the supraoptic nucleus in Parkinson's disease. Neurology 49:610-613. https://doi.org/10.1212/wnl.49.2.610

5. Aoun M, Tiranti V (2015) Mitochondria: a crossroads for lipid metabolism defect in neurodegeneration with brain iron accumulation diseases. Int J Biochem Cell Biol 63:25-31. https://doi. org/10.1016/j.biocel.2015.01.018

6. Ashburner M, Ball CA, Blake JA, Botstein D, Butler H, Cherry JM et al (2000) Gene ontology: tool for the unification of biology. Gene Ontol Consort Nat Genet 25:25-29. https://doi. org/10.1038/75556

7. Babin PL, Rao SNR, Chacko A, Alvina FB, Panwala A, Panwala $L$ et al (2018) Infantile neuroaxonal dystrophy: diagnosis and possible treatments. Front Genet 9:597. https://doi.org/10.3389/ fgene.2018.00597

8. Bandres-Ciga S, Diez-Fairen M, Kim JJ, Singleton AB (2020) Genetics of Parkinson's disease: an introspection of its journey towards precision medicine. Neurobiol Dis 137:104782. https:// doi.org/10.1016/j.nbd.2020.104782

9. Bartels T, Choi JG, Selkoe DJ (2011) alpha-Synuclein occurs physiologically as a helically folded tetramer that resists aggregation. Nature 477:107-110. https://doi.org/10.1038/nature10324

10. Bieri G, Brahic M, Bousset L, Couthouis J, Kramer NJ, Ma R et al (2019) LRRK2 modifies alpha-syn pathology and spread in mouse models and human neurons. Acta Neuropathol 137:961980. https://doi.org/10.1007/s00401-019-01995-0

11. Brüggemann N, Klein C (2013) Parkin type of early-onset Parkinson disease. GeneReviews. University of Washington, Seattle City

12. Burke JE, Dennis EA (2009) Phospholipase A2 biochemistry. Cardiovasc Drugs Ther 23:49-59. https://doi.org/10.1007/s1055 7-008-6132-9

13. Burre J (2015) The synaptic function of alpha-synuclein. J Parkinsons Dis 5:699-713. https://doi.org/10.3233/JPD-150642

14. Cachon-Gonzalez MB, Wang SZ, Ziegler R, Cheng SH, Cox TM (2014) Reversibility of neuropathology in Tay-Sachs-related diseases. Hum Mol Genet 23:730-748. https://doi.org/10.1093/ hmg/ddt 459

15. Cachon-Gonzalez MB, Zaccariotto E, Cox TM (2018) Genetics and therapies for GM2 gangliosidosis. Curr Gene Ther 18:68-89. https://doi.org/10.2174/1566523218666180404162622

16. Chen C, Turnbull DM, Reeve AK (2019) Mitochondrial dysfunction in parkinson's disease-cause or consequence? Biology (Basel). https://doi.org/10.3390/biology8020038

17. Chiba Y, Komori H, Takei S, Hasegawa-Ishii S, Kawamura N, Adachi K et al (2014) Niemann-Pick disease type C1 predominantly involving the frontotemporal region, with cortical and brainstem Lewy bodies: an autopsy case. Neuropathology 34:49-57. https://doi.org/10.1111/neup.12047

18. Cohlberg JA, Li J, Uversky VN, Fink AL (2002) Heparin and other glycosaminoglycans stimulate the formation of amyloid fibrils from alpha-synuclein in vitro. Biochemistry 41:15021511. https://doi.org/10.1021/bi011711s

19. Creed RB, Goldberg MS (2018) Analysis of alpha-Synuclein Pathology in PINK1 knockout rat brains. Front Neurosci 12:1034. https://doi.org/10.3389/fnins.2018.01034

20. Crichton RR, Dexter DT, Ward RJ (2011) Brain iron metabolism and its perturbation in neurological diseases. J Neural Transm (Vienna) 118:301-314. https://doi.org/10.1007/s0070 2-010-0470-z 
21. Cullen V, Lindfors M, Ng J, Paetau A, Swinton E, Kolodziej P et al (2009) Cathepsin D expression level affects alpha-synuclein processing, aggregation, and toxicity in vivo. Mol Brain 2:5. https://doi.org/10.1186/1756-6606-2-5

22. Debs R, Froissart R, Aubourg P, Papeix C, Douillard C, Degos B et al (2013) Krabbe disease in adults: phenotypic and genotypic update from a series of 11 cases and a review. J Inherit Metab Dis 36:859-868. https://doi.org/10.1007/s10545-012-9560-4

23. Del Tredici K, Ludolph AC, Feldengut S, Jacob C, Reichmann H, Bohl JR et al (2020) Fabry disease with concomitant lewy body disease. J Neuropathol Exp Neurol 79:378-392. https:// doi.org/10.1093/jnen/nlz139

24. Deng HX, Shi Y, Yang Y, Ahmeti KB, Miller N, Huang C et al (2016) Identification of TMEM230 mutations in familial Parkinson's disease. Nat Genet 48:733-739. https://doi.org/10.1038/ ng.3589

25. Dettmer U, Newman AJ, Soldner F, Luth ES, Kim NC, Saucken VE et al (2015) Parkinson-causing alpha-synuclein missense mutations shift native tetramers to monomers as a mechanism for disease initiation. Nat Commun 6:7314. https://doi.org/10.1038/ ncomms 8314

26. Do J, McKinney C, Sharma P, Sidransky E (2019) Glucocerebrosidase and its relevance to Parkinson disease. Mol Neurodegener 14:36. https://doi.org/10.1186/s13024-019-0336-2

27. Doherty KM, Hardy J (2013) Parkin disease and the Lewy body conundrum. Mov Disord 28:702-704. https://doi.org/10.1002/ mds. 25486

28. Erskine D, Reeve AK, Polvikoski T, Schaefer AM, Taylor RW, Lax NZ et al (2020) Lewy body pathology is more prevalent in older individuals with mitochondrial disease than controls. Acta Neuropathol 139:219-221. https://doi.org/10.1007/s00401-01902105-W

29. Fanning S, Selkoe D, Dettmer U (2020) Parkinson's disease: proteinopathy or lipidopathy? NPJ Parkinsons Dis 6:3. https://doi. org/10.1038/s41531-019-0103-7

30. Fernagut PO, Chesselet MF (2004) Alpha-synuclein and transgenic mouse models. Neurobiol Dis 17:123-130. https://doi. org/10.1016/j.nbd.2004.07.001

31. Ferreira CR, Gahl WA (2017) Lysosomal storage diseases. Transl Sci Rare Dis 2:1-71. https://doi.org/10.3233/TRD-160005

32. Fivenson EM, Lautrup S, Sun N, Scheibye-Knudsen M, Stevnsner T, Nilsen H et al (2017) Mitophagy in neurodegeneration and aging. Neurochem Int 109:202-209. https://doi. org/10.1016/j.neuint.2017.02.007

33. Fleming RE, Ponka P (2012) Iron overload in human disease. $\mathrm{N}$ Engl J Med 366:348-359. https://doi.org/10.1056/NEJMra1004 967

34. Frigerio R, Fujishiro H, Ahn TB, Josephs KA, Maraganore DM, DelleDonne A et al (2011) Incidental Lewy body disease: do some cases represent a preclinical stage of dementia with Lewy bodies? Neurobiol Aging 32:857-863. https://doi.org/10.1016/j. neurobiolaging.2009.05.019

35. Fusco G, De Simone A, Gopinath T, Vostrikov V, Vendruscolo M, Dobson CM et al (2014) Direct observation of the three regions in alpha-synuclein that determine its membrane-bound behaviour. Nat Commun 5:3827. https://doi.org/10.1038/ncomm s4827

36. Gao Y, Martinez-Cerdeno V, Hogan KJ, McLean CA, Lockhart PJ (2020) Clinical and neuropathological features associated with loss of RAB39B. Mov Disord 35:687-693. https://doi. org/10.1002/mds.27951

37. Ge P, Dawson VL, Dawson TM (2020) PINK1 and Parkin mitochondrial quality control: a source of regional vulnerability in Parkinson's disease. Mol Neurodegener 15:20. https://doi. org/10.1186/s13024-020-00367-7
38. Ge SX, Jung D, Yao R (2020) ShinyGO: a graphical gene-set enrichment tool for animals and plants. Bioinformatics 36:26282629. https://doi.org/10.1093/bioinformatics/btz931

39. Germain DP (2010) Fabry disease. Orphanet J Rare Dis 5:30. https://doi.org/10.1186/1750-1172-5-30

40. Giannandrea M, Bianchi V, Mignogna ML, Sirri A, Carrabino S, D'Elia E et al (2010) Mutations in the small GTPase gene RAB39B are responsible for X-linked mental retardation associated with autism, epilepsy, and macrocephaly. Am J Hum Genet 86:185-195. https://doi.org/10.1016/j.ajhg.2010.01.011

41. Girard M, Poupon V, Blondeau F, McPherson PS (2005) The DnaJ-domain protein RME-8 functions in endosomal trafficking. J Biol Chem 280:40135-40143. https://doi.org/10.1074/jbc. M505036200

42. Gorman GS, Schaefer AM, Ng Y, Gomez N, Blakely EL, Alston CL et al (2015) Prevalence of nuclear and mitochondrial DNA mutations related to adult mitochondrial disease. Ann Neurol 77:753-759. https://doi.org/10.1002/ana.24362

43. Graziano AC, Cardile V (2015) History, genetic, and recent advances on Krabbe disease. Gene 555:2-13. https://doi. org/10.1016/j.gene.2014.09.046

44. Gregory A, Lotia M, Jeong SY, Fox R, Zhen D, Sanford L et al (2019) Autosomal dominant mitochondrial membrane proteinassociated neurodegeneration (MPAN). Mol Genet Genomic Med 7:e00736. https://doi.org/10.1002/mgg3.736

45. Guo YP, Tang BS, Guo JF (2018) PLA2G6-associated neurodegeneration (PLAN): review of clinical phenotypes and genotypes. Front Neurol 9:1100. https://doi.org/10.3389/fneur.2018.01100

46. Hagberg B, Sourander P, Svennerholm L (1963) Diagnosis of Krabbe's infantile leucodystrophy. J Neurol Neurosurg Psychiatry 26:195-198. https://doi.org/10.1136/jnnp.26.3.195

47. Hamano K, Hayashi M, Shioda K, Fukatsu R, Mizutani S (2008) Mechanisms of neurodegeneration in mucopolysaccharidoses II and IIIB: analysis of human brain tissue. Acta Neuropathol 115:547-559. https://doi.org/10.1007/s00401-007-0325-3

48. Hance N, Ekstrand MI, Trifunovic A (2005) Mitochondrial DNA polymerase gamma is essential for mammalian embryogenesis. Hum Mol Genet 14:1775-1783. https://doi.org/10.1093/hmg/ ddi 184

49. Hartig MB, Iuso A, Haack T, Kmiec T, Jurkiewicz E, Heim $\mathrm{K}$ et al (2011) Absence of an orphan mitochondrial protein, c19orf12, causes a distinct clinical subtype of neurodegeneration with brain iron accumulation. Am J Hum Genet 89:543-550. https://doi.org/10.1016/j.ajhg.2011.09.007

50. Hatton C, Reeve A, Lax NZ, Blain A, Ng YS, El-Agnaf O et al (2020) Complex I reductions in the nucleus basalis of Meynert in Lewy body dementia: the role of Lewy bodies. Acta Neuropathol Commun 8:103. https://doi.org/10.1186/s40478-020-00985-8

51. Hayashida A, Li Y, Yoshino H, Daida K, Ikeda A, Ogaki K et al (2020) The identified clinical features of Parkinson's disease in homo-, heterozygous and digenic variants of PINK1. Neurobiol Aging. https://doi.org/10.1016/j.neurobiolaging.2020.06.017

52. Hayflick SJ, Kurian MA, Hogarth P (2018) Neurodegeneration with brain iron accumulation. Handb Clin Neurol 147:293-305. https://doi.org/10.1016/B978-0-444-63233-3.00019-1

53. Hoffmann B, Beck M, Sunder-Plassmann G, Borsini W, Ricci R, Mehta A et al (2007) Nature and prevalence of pain in Fabry disease and its response to enzyme replacement therapy-a retrospective analysis from the Fabry Outcome Survey. Clin J Pain 23:535-542. https://doi.org/10.1097/AJP.0b013e318074c986

54. Hogarth P, Gregory A, Kruer MC, Sanford L, Wagoner W, Natowicz MR et al (2013) New NBIA subtype: genetic, clini$\mathrm{cal}$, pathologic, and radiographic features of MPAN. Neurology 80:268-275. https://doi.org/10.1212/WNL.0b013e31827e07be 
55. Hou X, Watzlawik JO, Fiesel FC, Springer W (2020) Autophagy in Parkinson's disease. J Mol Biol 432:2651-2672. https://doi. org/10.1016/j.jmb.2020.01.037

56. Ikuno M, Yamakado H, Akiyama H, Parajuli LK, Taguchi K, Hara J et al (2019) GBA haploinsufficiency accelerates alphasynuclein pathology with altered lipid metabolism in a prodromal model of Parkinson's disease. Hum Mol Genet 28:1894-1904. https://doi.org/10.1093/hmg/ddz030

57. Itoh M, Hayashi M, Fujioka Y, Nagashima K, Morimatsu Y, Matsuyama H (2002) Immunohistological study of globoid cell leukodystrophy. Brain Dev 24:284-290. https://doi.org/10.1016/ s0387-7604(02)00057-8

58. Jaishy B, Abel ED (2016) Lipids, lysosomes, and autophagy. J Lipid Res 57:1619-1635. https://doi.org/10.1194/jlr.R067520

59. Jana BA, Chintamaneni PK, Krishnamurthy PT, Wadhwani A, Mohankumar SK (2019) Cytosolic lipid excess-induced mitochondrial dysfunction is the cause or effect of high fat dietinduced skeletal muscle insulin resistance: a molecular insight. Mol Biol Rep 46:957-963. https://doi.org/10.1007/s1103 3-018-4551-7

60. Jellinger KA, Korczyn AD (2018) Are dementia with Lewy bodies and Parkinson's disease dementia the same disease? BMC Med 16:34. https://doi.org/10.1186/s12916-018-1016-8

61. Karkheiran S, Shahidi GA, Walker RH, Paisan-Ruiz C (2015) PLA2G6-associated Dystonia-Parkinsonism: case report and literature review. Tremor Other Hyperkinet Mov (N Y) 5:317. https://doi.org/10.7916/D84Q7T4W

62. Keilani S, Lun Y, Stevens AC, Williams HN, Sjoberg ER, Khanna R et al (2012) Lysosomal dysfunction in a mouse model of Sandhoff disease leads to accumulation of ganglioside-bound amyloid-beta peptide. J Neurosci 32:5223-5236. https://doi. org/10.1523/JNEUROSCI.4860-11.2012

63. Kestenbaum M, Alcalay RN (2017) Clinical Features of LRRK2 carriers with Parkinson's disease. Adv Neurobiol 14:31-48. https ://doi.org/10.1007/978-3-319-49969-7_2

64. Kiely AP, Ling H, Asi YT, Kara E, Proukakis C, Schapira AH et al (2015) Distinct clinical and neuropathological features of G51D SNCA mutation cases compared with SNCA duplication and H50Q mutation. Mol Neurodegener 10:41. https://doi. org/10.1186/s13024-015-0038-3

65. Kim MJ, Deng HX, Wong YC, Siddique T, Krainc D (2017) The Parkinson's disease-linked protein TMEM230 is required for Rab8a-mediated secretory vesicle trafficking and retromer trafficking. Hum Mol Genet 26:729-741. https://doi.org/10.1093/ hmg/ddw413

66. Konno T, Ross OA, Puschmann A, Dickson DW, Wszolek ZK (2016) Autosomal dominant Parkinson's disease caused by SNCA duplications. Parkinsonism Relat Disord 22(Suppl 1):S16. https://doi.org/10.1016/j.parkreldis.2015.09.007

67. Koss DJ, Bondarevaite O, Adams S, Leite M, Giorgini F, Attems $\mathrm{J}$ et al (2020) RAB39B is redistributed in dementia with Lewy bodies and is sequestered within abeta plaques and Lewy bodies. Brain Pathol. https://doi.org/10.1111/bpa.12890

68. Kruer MC (2013) The neuropathology of neurodegeneration with brain iron accumulation. Int Rev Neurobiol 110:165-194. https ://doi.org/10.1016/B978-0-12-410502-7.00009-0

69. Lou HO, Reske-Nielsen E (1971) The central nervous system in Fabry's disease. A clinical, pathological, and biochemical investigation. Arch Neurol 25:351-359. https://doi.org/10.1001/archn eur.1971.00490040077009

70. Lu XH, Fleming SM, Meurers B, Ackerson LC, Mortazavi F, Lo $\mathrm{V}$ et al (2009) Bacterial artificial chromosome transgenic mice expressing a truncated mutant parkin exhibit age-dependent hypokinetic motor deficits, dopaminergic neuron degeneration, and accumulation of proteinase K-resistant alpha-synuclein.
J Neurosci 29:1962-1976. https://doi.org/10.1523/JNEUR OSCI.5351-08.2009

71. Lyon G, Hagberg B, Evrard P, Allaire C, Pavone L, Vanier M (1991) Symptomatology of late onset Krabbe's leukodystrophy: the European experience. Dev Neurosci 13:240-244. https://doi. org/10.1159/000112167

72. Mahul-Mellier AL, Burtscher J, Maharjan N, Weerens L, Croisier M, Kuttler F et al (2020) The process of Lewy body formation, rather than simply alpha-synuclein fibrillization, is one of the major drivers of neurodegeneration. Proc Natl Acad Sci U S A 117:4971-4982. https://doi.org/10.1073/pnas.1913904117

73. Markopoulou K, Dickson DW, McComb RD, Wszolek ZK, Katechalidou L, Avery L et al (2008) Clinical, neuropathological and genotypic variability in SNCA A53T familial Parkinson's disease. Variability in familial Parkinson's disease. Acta Neuropathol 116:25-35. https://doi.org/10.1007/s00401-008-0372-4

74. Martinez-Vicente M, Talloczy Z, Kaushik S, Massey AC, Mazzulli J, Mosharov EV et al (2008) Dopamine-modified alphasynuclein blocks chaperone-mediated autophagy. J Clin Invest 118:777-788. https://doi.org/10.1172/JCI32806

75. McKeith IG, Boeve BF, Dickson DW, Halliday G, Taylor JP, Weintraub D et al (2017) Diagnosis and management of dementia with Lewy bodies: Fourth consensus report of the DLB Consortium. Neurology 89:88-100. https://doi.org/10.1212/WNL.00000 00000004058

76. Meade RM, Fairlie DP, Mason JM (2019) Alpha-synuclein structure and Parkinson's disease - lessons and emerging principles. Mol Neurodegener 14:29. https://doi.org/10.1186/s1302 4-019-0329-1

77. Mi H, Muruganujan A, Ebert D, Huang X, Thomas PD (2019) PANTHER version 14: more genomes, a new PANTHER GOslim and improvements in enrichment analysis tools. Nucl Acids Res 47:D419-D426. https://doi.org/10.1093/nar/gky1038

78. Milber JM, Noorigian JV, Morley JF, Petrovitch H, White L, Ross GW et al (2012) Lewy pathology is not the first sign of degeneration in vulnerable neurons in Parkinson disease. Neurology 79:2307-2314. https://doi.org/10.1212/WNL.0b013e318278fe3 2

79. Mole SE, Cotman SL (2015) Genetics of the neuronal ceroid lipofuscinoses (Batten disease). Biochim Biophys Acta 1852:2237-2241. https://doi.org/10.1016/j.bbadis.2015.05.011

80. Montgomery MK, De Nardo W, Watt MJ (2019) Impact of lipotoxicity on tissue "Cross Talk" and metabolic regulation. Physiology (Bethesda) 34:134-149. https://doi.org/10.1152/ physiol.00037.2018

81. Mori A, Imai Y, Hattori N (2020) Lipids: key players that modulate alpha-synuclein toxicity and neurodegeneration in Parkinson's disease. Int J Mol Sci. https://doi.org/10.3390/ ijms21093301

82. Morris AM, Watzky MA, Agar JN, Finke RG (2008) Fitting neurological protein aggregation kinetic data via a 2-step, minimal/"Ockham's razor" model: the Finke-Watzky mechanism of nucleation followed by autocatalytic surface growth. Biochemistry 47:2413-2427. https://doi.org/10.1021/bi701 $899 y$

83. Nelson MP, Tse TE, O'Quinn DB, Percival SM, Jaimes EA, Warnock DG et al (2014) Autophagy-lysosome pathway associated neuropathology and axonal degeneration in the brains of alpha-galactosidase A-deficient mice. Acta Neuropathol Commun 2:20. https://doi.org/10.1186/2051-5960-2-20

84. Neumann J, Bras J, Deas E, O'Sullivan SS, Parkkinen L, Lachmann RH et al (2009) Glucocerebrosidase mutations in clinical and pathologically proven Parkinson's disease. Brain 132:17831794. https://doi.org/10.1093/brain/awp044

85. Nuber S, Rajsombath M, Minakaki G, Winkler J, Muller CP, Ericsson $\mathrm{M}$ et al (2018) Abrogating native alpha-synuclein 
tetramers in mice causes a L-DOPA-responsive motor syndrome closely resembling Parkinson's disease. Neuron 100(75-90):e75. https://doi.org/10.1016/j.neuron.2018.09.014

86. Ortiz A, Germain DP, Desnick RJ, Politei J, Mauer M, Burlina A et al (2018) Fabry disease revisited: Management and treatment recommendations for adult patients. Mol Genet Metab 123:416-427. https://doi.org/10.1016/j.ymgme.2018.02.014

87. Osellame LD, Blacker TS, Duchen MR (2012) Cellular and molecular mechanisms of mitochondrial function. Best Pract Res Clin Endocrinol Metab 26:711-723. https://doi.org/10.1016/j. beem.2012.05.003

88. Outeiro TF, Koss DJ, Erskine D, Walker L, Kurzawa-Akanbi M, Burn D et al (2019) Dementia with Lewy bodies: an update and outlook. Mol Neurodegener 14:5. https://doi.org/10.1186/s1302 4-019-0306-8

89. Outeiro TF, Lindquist S (2003) Yeast cells provide insight into alpha-synuclein biology and pathobiology. Science 302:17721775. https://doi.org/10.1126/science.1090439

90. Paisan-Ruiz C, Li A, Schneider SA, Holton JL, Johnson R, Kidd D et al (2012) Widespread Lewy body and tau accumulation in childhood and adult onset dystonia-parkinsonism cases with PLA2G6 mutations. Neurobiol Aging 33:814-823. https://doi. org/10.1016/j.neurobiolaging.2010.05.009

91. Palikaras K, Lionaki E, Tavernarakis N (2018) Mechanisms of mitophagy in cellular homeostasis, physiology and pathology. Nat Cell Biol 20:1013-1022. https://doi.org/10.1038/s4155 6-018-0176-2

92. Papadimitriou D, Antonelou R, Miligkos M, Maniati M, Papagiannakis N, Bostantjopoulou S et al (2016) Motor and nonmotor features of carriers of the p. A53T alpha-synuclein mutation: a longitudinal study. Mov Disord 31:1226-1230. https://doi. org/10.1002/mds.26615

93. Perrin RJ, Woods WS, Clayton DF, George JM (2001) Exposure to long chain polyunsaturated fatty acids triggers rapid multimerization of synucleins. J Biol Chem 276:41958-41962. https:// doi.org/10.1074/jbc.M105022200

94. Polymeropoulos MH, Lavedan C, Leroy E, Ide SE, Dehejia A, Dutra A et al (1997) Mutation in the alpha-synuclein gene identified in families with Parkinson's disease. Science 276:20452047. https://doi.org/10.1126/science.276.5321.2045

95. Quadri M, Mandemakers W, Grochowska MM, Masius R, Geut H, Fabrizio E et al (2018) LRP10 genetic variants in familial Parkinson's disease and dementia with Lewy bodies: a genomewide linkage and sequencing study. Lancet Neurol 17:597-608. https://doi.org/10.1016/S1474-4422(18)30179-0

96. Raninga PV, Di Trapani G, Tonissen KF (2017) The Multifaceted Roles of DJ-1 as an Antioxidant. Adv Exp Med Biol 1037:67-87. https://doi.org/10.1007/978-981-10-6583-5_6

97. Repici M, Giorgini F (2019) DJ-1 in Parkinson's disease: clinical insights and therapeutic perspectives. J Clin Med. https://doi. org $/ 10.3390 / \mathrm{jcm} 8091377$

98. Rivero-Rios P, Romo-Lozano M, Fasiczka R, Naaldijk Y, Hilfiker S (2020) LRRK2-related Parkinson's disease due to altered endolysosomal biology with variable lewy body pathology: a hypothesis. Front Neurosci 14:556. https://doi.org/10.3389/fnins .2020 .00556

99. Saito Y, Suzuki K, Hulette CM, Murayama S (2004) Aberrant phosphorylation of alpha-synuclein in human Niemann-Pick type C1 disease. J Neuropathol Exp Neurol 63:323-328. https://doi. org/10.1093/jnen/63.4.323

100. Samaranch L, Lorenzo-Betancor O, Arbelo JM, Ferrer I, Lorenzo $\mathrm{E}$, Irigoyen $\mathrm{J}$ et al (2010) PINK1-linked parkinsonism is associated with Lewy body pathology. Brain 133:1128-1142. https:// doi.org/10.1093/brain/awq051

101. Sanderson JB, De S, Jiang H, Rovere M, Jin M, Zaccagnini L et al (2020) Analysis of alpha-synuclein species enriched from cerebral cortex of humans with sporadic dementia with Lewy bodies. Brain Commun 2:010. https://doi.org/10.1093/brain comms/fcaa010

102. Scarlata S, Golebiewska U (2014) Linking alpha-synuclein properties with oxidation: a hypothesis on a mechanism underling cellular aggregation. J Bioenerg Biomembr 46:93-98. https:// doi.org/10.1007/s10863-014-9540-5

103. Schneider SA, Alcalay RN (2017) Neuropathology of genetic synucleinopathies with parkinsonism: review of the literature. Mov Disord 32:1504-1523. https://doi.org/10.1002/mds.27193

104. Schneider SA, Dusek P, Hardy J, Westenberger A, Jankovic J, Bhatia KP (2013) Genetics and pathophysiology of neurodegeneration with brain iron accumulation (NBIA). Curr Neuropharmacol 11:59-79. https://doi.org/10.2174/157015913804999469

105. Sedlackova L, Otten EG, Scialo F, Shapira D, Kataura T, Carroll B et al (2020) Autophagy promotes cell and organismal survival by maintaining NAD $(\mathrm{H})$ pools. Biorxiv 29:803

106. Seidel K, Schols L, Nuber S, Petrasch-Parwez E, Gierga K, Wszolek Z et al (2010) First appraisal of brain pathology owing to A30P mutant alpha-synuclein. Ann Neurol 67:684-689. https ://doi.org/10.1002/ana.21966

107. Seirafi M, Kozlov G, Gehring K (2015) Parkin structure and function. FEBS J 282:2076-2088. https://doi.org/10.1111/ febs. 13249

108. Shachar T, Lo CB, Recchia A, Wiessner C, Raas-Rothschild A, Futerman AH (2011) Lysosomal storage disorders and Parkinson's disease: Gaucher disease and beyond. Mov Disord 26:1593-1604. https://doi.org/10.1002/mds.23774

109. Shahmoradian SH, Lewis AJ, Genoud C, Hench J, Moors TE, Navarro PP et al (2019) Lewy pathology in Parkinson's disease consists of crowded organelles and lipid membranes. Nat Neurosci 22:1099-1109. https://doi.org/10.1038/s41593-019-0423-2

110. Shi CH, Zhang SY, Yang ZH, Yang J, Shang DD, Mao CY et al (2016) A novel RAB39B gene mutation in X-linked juvenile parkinsonism with basal ganglia calcification. Mov Disord 31:19051909. https://doi.org/10.1002/mds.26828

111. Sidransky E (2012) Gaucher disease: insights from a rare Mendelian disorder. Discov Med 14:273-281

112. Siintola E, Partanen S, Stromme P, Haapanen A, Haltia M, Maehlen J et al (2006) Cathepsin D deficiency underlies congenital human neuronal ceroid-lipofuscinosis. Brain 129:14381445. https://doi.org/10.1093/brain/awl107

113. Smith BR, Santos MB, Marshall MS, Cantuti-Castelvetri L, Lopez-Rosas A, Li G et al (2014) Neuronal inclusions of alpha-synuclein contribute to the pathogenesis of Krabbe disease. J Pathol 232:509-521. https://doi.org/10.1002/path.4328

114. Smith NJ, Winstone AM, Stellitano L, Cox TM, Verity CM (2012) GM2 gangliosidosis in a UK study of children with progressive neurodegeneration: 73 cases reviewed. Dev Med Child Neurol 54:176-182. https://doi.org/10.111 1/j.1469-8749.2011.04160.x

115. Spillantini MG, Schmidt ML, Lee VM, Trojanowski JQ, Jakes R, Goedert M (1997) Alpha-synuclein in Lewy bodies. Nature 388:839-840. https://doi.org/10.1038/42166

116. Steele JC, Guella I, Szu-Tu C, Lin MK, Thompson C, Evans $\mathrm{DM}$ et al (2015) Defining neurodegeneration on Guam by targeted genomic sequencing. Ann Neurol 77:458-468. https:// doi.org/10.1002/ana.24346

117. Steger M, Diez F, Dhekne HS, Lis P, Nirujogi RS, Karayel O et al (2017) Systematic proteomic analysis of LRRK2-mediated Rab GTPase phosphorylation establishes a connection to ciliogenesis. Elife. https://doi.org/10.7554/eLife.31012

118. Steger M, Tonelli F, Ito G, Davies P, Trost M, Vetter M et al (2016) Phosphoproteomics reveals that Parkinson's disease kinase LRRK2 regulates a subset of Rab GTPases. Elife. https ://doi.org/10.7554/eLife.12813 
119. Stojkovska I, Krainc D, Mazzulli JR (2018) Molecular mechanisms of alpha-synuclein and GBA1 in Parkinson's disease. Cell Tissue Res 373:51-60. https://doi.org/10.1007/s0044 1-017-2704-y

120. Stumpf JD, Saneto RP, Copeland WC (2013) Clinical and molecular features of POLG-related mitochondrial disease. Cold Spring Harb Perspect Biol 5:a011395. https://doi. org/10.1101/cshperspect.a011395

121. Sugiyama T, Kumagai H, Morikawa Y, Wada Y, Sugiyama A, Yasuda K et al (2000) A novel low-density lipoprotein receptor-related protein mediating cellular uptake of apolipoprotein E-enriched beta-VLDL in vitro. Biochemistry 39:1581715825. https://doi.org/10.1021/bi001583s

122. Sumi-Akamaru H, Beck G, Shinzawa K, Kato S, Riku Y, Yoshida $\mathrm{M}$ et al (2016) High expression of alpha-synuclein in damaged mitochondria with PLA2G6 dysfunction. Acta Neuropathol Commun 4:27. https://doi.org/10.1186/s4047 8-016-0298-3

123. Sun A (2018) Lysosomal storage disease overview. Ann Transl Med 6:476. https://doi.org/10.21037/atm.2018.11.39

124. Suzuki K, Iseki E, Togo T, Yamaguchi A, Katsuse O, Katsuyama K et al (2007) Neuronal and glial accumulation of alphaand beta-synucleins in human lipidoses. Acta Neuropathol 114:481-489. https://doi.org/10.1007/s00401-007-0264-z

125. Tabira T, Goto I, Kuroiwa Y, Kikuchi M (1974) Neuropathological and biochemical studies in Fabry's disease. Acta Neuropathol 30:345-354. https://doi.org/10.1007/BF00697017

126. Taipa R, Pereira C, Reis I, Alonso I, Bastos-Lima A, MeloPires M et al (2016) DJ-1 linked parkinsonism (PARK7) is associated with Lewy body pathology. Brain 139:1680-1687. https://doi.org/10.1093/brain/aww080

127. Takanashi M, Li Y, Hattori N (2016) Absence of Lewy pathology associated with PINK1 homozygous mutation. Neurology 86:2212-2213. https://doi.org/10.1212/WNL.0000000000 002744

128. The Gene Ontology C (2019) The Gene Ontology Resource: 20 years and still GOing strong. Nucl Acids Res 47:D330-D338. https://doi.org/10.1093/nar/gky1055

129. Vergouw LJM, Geut H, Breedveld G, Kuipers DJS, Quadri M, Brain BM et al (2020) Clinical and pathological phenotypes of LRP10 Variant Carriers With Dementia. J Alzheimers Dis 76:1161-1170. https://doi.org/10.3233/JAD-200318

130. Viennet T, Wordehoff MM, Uluca B, Poojari C, Shaykhalishahi H, Willbold D et al (2018) Structural insights from lipid-bilayer nanodiscs link alpha-Synuclein membrane-binding modes to amyloid fibril formation. Commun Biol 1:44. https://doi. org/10.1038/s42003-018-0049-z
131. Vilarino-Guell C, Rajput A, Milnerwood AJ, Shah B, Szu-Tu C, Trinh J et al (2014) DNAJC13 mutations in Parkinson disease. Hum Mol Genet 23:1794-1801. https://doi.org/10.1093/hmg/ ddt570

132. Wanders RJ, Waterham HR, Ferdinandusse S (2015) Metabolic interplay between peroxisomes and other subcellular organelles including mitochondria and the endoplasmic reticulum. Front Cell Dev Biol 3:83. https://doi.org/10.3389/fcell.2015.00083

133. Wilson GR, Sim JC, McLean C, Giannandrea M, Galea CA, Riseley JR et al (2014) Mutations in RAB39B cause X-linked intellectual disability and early-onset Parkinson disease with alpha-synuclein pathology. Am J Hum Genet 95:729-735. https ://doi.org/10.1016/j.ajhg.2014.10.015

134. Wong K, Sidransky E, Verma A, Mixon T, Sandberg GD, Wakefield LK et al (2004) Neuropathology provides clues to the pathophysiology of Gaucher disease. Mol Genet Metab 82:192-207. https://doi.org/10.1016/j.ymgme.2004.04.011

135. Yoshida S, Hasegawa T, Suzuki M, Sugeno N, Kobayashi J, Ueyama M et al (2018) Parkinson's disease-linked DNAJC13 mutation aggravates alpha-synuclein-induced neurotoxicity through perturbation of endosomal trafficking. Hum Mol Genet 27:823-836. https://doi.org/10.1093/hmg/ddy003

136. Yu XH, Jiang N, Yao PB, Zheng XL, Cayabyab FS, Tang CK (2014) NPC1, intracellular cholesterol trafficking and atherosclerosis. Clin Chim Acta 429:69-75. https://doi.org/10.1016/j. cca.2013.11.026

137. Zarranz JJ, Alegre J, Gomez-Esteban JC, Lezcano E, Ros R, Ampuero I et al (2004) The new mutation, E46K, of alpha-synuclein causes Parkinson and Lewy body dementia. Ann Neurol 55:164-173. https://doi.org/10.1002/ana.10795

138. Zelei T, Csetneki K, Voko Z, Siffel C (2018) Epidemiology of Sanfilippo syndrome: results of a systematic literature review. Orphanet J Rare Dis 13:53. https://doi.org/10.1186/s1302 3-018-0796-4

139. Zervas M, Dobrenis K, Walkley SU (2001) Neurons in NiemannPick disease type $\mathrm{C}$ accumulate gangliosides as well as unesterified cholesterol and undergo dendritic and axonal alterations. J Neuropathol Exp Neurol 60:49-64. https://doi.org/10.1093/ jnen/60.1.49

Publisher's Note Springer Nature remains neutral with regard to jurisdictional claims in published maps and institutional affiliations. 